\title{
In reply: The use of tranexamic acid in pediatric cardiac surgery: we really need more
}

\author{
Yuichiro Toda $\cdot$ Kazuyoshi Shimizu . \\ Kiyoshi Morita
}

Received: 18 November 2011 / Accepted: 23 November 2011/Published online: 17 December 2011

(C) Japanese Society of Anesthesiologists 2011

To the Editor:

I would like to thank Dr. Faraoni and colleagues for their comments on our work. They raised important questions about tranexamic acid (TXA) usage in pediatric cardiac surgery. As they pointed out, there are still many concerns about the administration of TXA in congenital heart surgery (CHS). First, we do not know how often fibrinolysis occurs in pediatric cardiopulmonary bypass. Although its frequency in pediatric heart surgery was reported to be $16 \%$ in one article [1], there are few other reports in the literature in which the incidence of fibrinolysis in CHS is stated. Furthermore, the recent development of products related to cardiopulmonary bypass can reduce the frequency and degree of fibrinolysis, and thus perhaps improve the outcome in patients with congenital heart disease [2]. Second, we do not know the target concentration of TXA needed to inhibit fibrinolysis. The required concentration of TXA has only been stated in a few articles published many decades ago [3]. We really need studies confirming the appropriate concentration of TXA, which could be $20 \mu \mathrm{g} / \mathrm{ml}$ [4] or $334 \mu \mathrm{M}$ (approximately $52 \mu \mathrm{g}$ / $\mathrm{ml}$ ) [5]. Moreover, we do not have data for a pediatric population in which a much larger volume is used to prime cardiopulmonary circuits and considerable hemodilution is expected. Our protocol for administering TXA seems to be expected to have a higher concentration than those in previous studies, although it cannot be easily compared

This author's reply refers to the letter to the editor at doi:10.1007/s00540-011-1298-x.

Y. Toda $(\varangle) \cdot$ K. Shimizu $\cdot$ K. Morita

Department of Anesthesiology and Resuscitology,

Okayama University Hospital, 2-5-1 Shikata-cho,

Kita-ku, Okayama, Okayama 700-8558, Japan

e-mail: ytoda-pccs@umin.ac.jp with adult studies. Since side effects of TXA are considered not to be negligible, the dosing scheme for TXA in CHS should be determined by an appropriate study in the future.

Finally, we thank Dr. Faraoni and colleagues again, and we appreciate their helpful comments.

\section{References}

1. Williams GD, Bratton SL, Riley EC, Ramamoorthy C. Association between age and blood loss in children undergoing open heart operations. Ann Thorac Surg. 1998;66:870-5 (discussion 875-76).

2. Jensen E, Andreasson S, Bengtsson A, Berggren H, Ekroth R, Larsson LE, Ouchterlony J. Changes in hemostasis during pediatric heart surgery: impact of a biocompatible heparin-coated perfusion system. Ann Thorac Surg. 2004;77:962-7.

3. Andersson L, Nilsoon IM, Colleen S, Granstrand B, Melander B. Role of urokinase and tissue activator in sustaining bleeding and the management thereof with EACA and AMCA. Ann N Y Acad Sci. 1968;146:642-58.

4. Nuttall GA, Gutierrez MC, Dewey JD, Johnson ME, Oyen LJ, Hanson AC, Oliver WC Jr. A preliminary study of a new tranexamic acid dosing schedule for cardiac surgery. J Cardiothorac Vasc Anesth. 2008;22:230-5.

5. Dowd NP, Karski JM, Cheng DC, Carroll JA, Lin Y, James RL, Butterworth J. Pharmacokinetics of tranexamic acid during cardiopulmonary bypass. Anesthesiology. 2002;97:390-9. 